\title{
Impact of various media and organic carbon sources on biofuel production potential from Chlorella spp.
}

\author{
Amit Kumar Sharma ${ }^{1}$ Pradeepta Kumar Sahoo ${ }^{1} \cdot$ Shailey Singhal $^{2}$. \\ Alok Patel ${ }^{3}$
}

Received: 29 February 2016/Accepted: 24 May 2016/Published online: 31 May 2016

(c) The Author(s) 2016. This article is published with open access at Springerlink.com

\begin{abstract}
In this study, five Chlorella species (Chlorella vulgaris, Chlorella minutissima, Chlorella pyrenoidosa, Chlorella sp.1 and Chlorella sp.2) were grown in various nutrient medium including BG-11, BBM, Fog's medium and $\mathrm{M}_{4} \mathrm{~N}$ medium for the evolution of biomass and lipid production potential. Among the tested medium, BG-11 was found most economical and efficient medium for all Chlorella species. To see the impact of organic carbon sources on lipid production potential, all microalgae species were also cultured in selected medium (BG-11) with different organic carbon sources like glucose, glycerol, sodium acetate, and sucrose under mixotrophic condition. The results showed that all Chlorella species performs better under mixotrophic condition, but Chlorella vulgaris
\end{abstract}

Electronic supplementary material The online version of this article (doi:10.1007/s13205-016-0434-6) contains supplementary material, which is available to authorized users.

Pradeepta Kumar Sahoo

pksahoo.iitd@gmail.com

Amit Kumar Sharma

amit.orgchemistry@gmail.com

Shailey Singhal

shailey@ddn.upes.ac.in

Alok Patel

biotechalok@gmail.com

1 Biofuel Research Laboratory, Institute of Alternative Energy Research, University of Petroleum and Energy Studies, Bidholi, Dehradun, Uttrakhand 248007, India

2 Department of Chemistry, University of Petroleum and Energy Studies, Bidholi, Dehradun, Uttrakhand 248007, India

3 Department of Biotechnology, Molecular Microbiology Laboratory, IIT Roorkee, Roorkee 247667, India achieved maximum lipid productivity (3.5 folds higher) in glycerol supplemented culture medium than control medium among all species.

Keywords Chlorella sp. · Culture medium · Organic carbon sources $\cdot$ Lipid production $\cdot$ Biofuel

\section{Introduction}

Current research scenario has been focused on sustainable and renewable biofuels due to depletion of world crude oil reserves and hike in fossil fuels prices (Williams et al. 2009; Sajid et al. 2016). Among various sources of renewable energy, microalgae are getting more attention as liquid (biodiesel and bioethanol) and gaseous (biogas and hydrogen) sources of renewable fuels (Prajapati et al. 2014). Microalgae has various advantages over other sources, such as having high lipid productivity, devoid of any seasonal changes, less water and land requirement and greater photosynthetic efficiency, which make it more sustainable. Besides autotrophic growth, microalgae also grow well on various cheap carbon sources such as wastewater (Prajapati et al. 2013), in hetrotrophic mode.

Cultivation condition of microalgae affects both the biomass and lipid productivity along with cost-effectiveness. The composition of nutrient media (Nitrogen, carbon, phosphorus and trace metals) is one of the most significant factors that affect growth parameter and biochemical composition of microalgae (Lam and Lee 2012; Li et al. 2012; Prathima Devi et al. 2012; Wang et al. 2014; Lin and $\mathrm{Wu}$ 2015). The effect of different media composition (Allen medium, Bold's Basal Medium, BG-11 medium, FSi medium, SK medium, Walne's medium) on growth rate and lipid accumulation of $C$. pyrenoidosa was studied by 
Wang et al. (2014) and found F-Si medium is the best and most economical medium for $C$. pyrenoidosa under outdoor conditions (Wang et al. 2014). Huerlimann et al. cultured Isochrysis sp., Nannochloropsis sp., Tetraselmis sp., and Rhodomonas sp. microalgae species in three growth medium (L1, f/2, and K-medium) to study the differences in biomass yield, lipid content and lipid productivity. Hence, it is necessitated to investigate and select suitable medium and nutrient level for the cultivation of microalgae with rapid growth and higher lipid content (Huerlimann et al. 2010). In addition, it was also reported that biomass and lipid production of microalgae is also greatly affected by different carbon sources and concentration (Cheirsilp and Torpee 2012; Lam and Lee 2012; Gim et al. 2014; Choi and Yu 2015). The mixotrophic cultivation, using both organic and inorganic $\left(\mathrm{CO}_{2}\right)$ carbon sources in presence of light, is a good strategy to obtain large biomass and higher lipid content (Gao et al. 2010; Bhatnagar et al. 2011; Choi and Yu 2015; Lin and Wu 2015).

The aim of this study is to select and modify growth medium for enhancing biomass and lipid production of Chlorella vulgaris, Chlorella minutissima, Chlorella pyrenoidosa, Chlorella sp. 1 and Chlorella sp. 2 towards biodiesel production. First, to identify suitable medium, all Chlorella species were grown in BG-11, BBM, Fogg's medium and $\mathrm{M}_{4} \mathrm{~N}$. Then, to study the effect of different carbon sources (Fructose, Glycerol, Glucose and Sodium acetate) on growth and lipid content, all the five Chlorella species were cultivated in BG-11 nutrient medium under mixotrophic condition.

\section{Material and methodology}

\section{Microalgae strain and pre-cultivation conditions}

Pure cultures of Chlorella vulgaris, Chlorella minutissima, Chlorella pyrenoidosa and Chlorella sp. 2 were procured from Vivekananda Institute of Algal Technology (VIAT), Chennai (India); Centre for Conservation and Utilization of Blue Green Algae, IARI New Delhi (India), National Collection of Industrial Microorganisms (NCIM), National Chemical Laboratory, Pune (India) and Yogi Vemana University, Vemanapuram, Kadapa, Andhra Pradesh, India, respectively. A microalgal species was also collected from a pond nearby the area of Dehradun, Uttarakhand and purified at agar plates by standard protocol (Guillard 2005). It was identified morphologically as Chlorella sp. and is represented here as "Chlorella sp. 1", whereas algae procured from Yogi Vemana University, Vemanapuram, Kadapa, Andhra Pradesh, is represented as "Chlorella sp. 2 " in this study. The stock cultures of all the strains were maintained regularly on agar slants using sterilized BBM medium (with initial $\mathrm{pH}$ of 6.8) under laboratory conditions at $24{ }^{\circ} \mathrm{C}\left( \pm 1{ }^{\circ} \mathrm{C}\right)$ under $(\sim 2500 \mathrm{~lx})$ light intensity and $16 / 8$ light dark cycle. All the strains were transferred from agar slant into a liquid medium and incubated under the same conditions of temperature and light in photobioreactor. Liquid cultures were used as the inoculum for the designed experiments. The morphology of pure strains was regularly examined under an optical microscope and photographed by a Nikon Eclipse Ci-E microscope (serial no. 59E05).

\section{Screening and identification of efficient growth media for maximum lipid productivity}

The growth performance and lipid productivity of microalgae is highly influenced by the composition of medium used for cultivation. Four media that have been used for photoautotrophic culture of Chlorella species include Bold's basal medium (BBM), BG-11, Fog's medium and M4N.

Bold's basal medium (Ilavarasi et al. 2011); $\mathrm{NaNO}_{3}$ $250 \mathrm{mg} / \mathrm{L}, \mathrm{K}_{2} \mathrm{HPO}_{4} 75 \mathrm{mg} / \mathrm{L}, \mathrm{MgSO}_{4} .7 \mathrm{H} 2 \mathrm{O} 75 \mathrm{mg} / \mathrm{L}$, $\mathrm{CaCl}_{2} .2 \mathrm{H}_{2} \mathrm{O} 25 \mathrm{mg} / \mathrm{L}, \mathrm{KH}_{2} \mathrm{PO}_{4} 175 \mathrm{mg} / \mathrm{L}, \mathrm{NaCl} 25 \mathrm{mg} / \mathrm{L}$, Alkaline EDTA solution $1 \mathrm{mg} / \mathrm{L}$ (Alkaline EDTA solution: $5 \mathrm{~g} \mathrm{Na}_{2}$-EDTA and $3.1 \mathrm{~g} \mathrm{KOH}$ in $100 \mathrm{ml}$ distilled water), Acidified Iron solution $1 \mathrm{mg} / \mathrm{L}$ (Acidified Iron solution $\mathrm{FeSO}_{4} .7 \mathrm{H} 2 \mathrm{O} .498 \mathrm{~g}$ and $0.1 \mathrm{ml} \mathrm{H}_{2} \mathrm{SO}_{4}$ in $100 \mathrm{ml}$ distilled water) Trace metal solution $1 \mathrm{ml} / \mathrm{L}$ (Trace metal solution: $\mathrm{MnCl}_{2} .4 \mathrm{H}_{2} \mathrm{O} \quad 1.44 \mathrm{~g} / \mathrm{L}, \quad \mathrm{ZnSO}_{4} .7 \mathrm{H}_{2} \mathrm{O} \quad 8.82 \mathrm{~g} / \mathrm{L}, \quad\left(\mathrm{NH}_{4}\right)_{6}$ $\mathrm{Mo}_{7} \mathrm{O}_{24} .2 \mathrm{H}_{2} \mathrm{O} \quad 0.88 \mathrm{~g} / \mathrm{L}, \quad \mathrm{Co}\left(\mathrm{NO}_{3}\right)_{2} \cdot 6 \mathrm{H}_{2} \mathrm{O} \quad 0.49 \mathrm{~g} / \mathrm{L}$, $\mathrm{CuSO}_{4} .5 \mathrm{H}_{2} \mathrm{O} 1.57 \mathrm{~g} / \mathrm{L}$ ).

BG-11 medium (Ilavarasi et al. 2011); $\mathrm{NaNO}_{3} 1500 \mathrm{mg} /$ $\mathrm{L}, \mathrm{K}_{2} \mathrm{HPO}_{4} 40 \mathrm{mg} / \mathrm{L}^{\prime} \mathrm{MgSO}_{4} .7 \mathrm{H} 2 \mathrm{O} 75 \mathrm{mg} / \mathrm{L}, \mathrm{CaCl}_{2} .2 \mathrm{H}_{2} \mathrm{O}$ $36 \mathrm{mg} / \mathrm{L}$, Citric acid $6 \mathrm{mg} / \mathrm{L}$, Trace metal solution $1 \mathrm{ml} / \mathrm{L}$ (Trace metal solution: $\mathrm{FeC}_{6} \mathrm{H}_{5} \mathrm{O}_{7} \cdot \mathrm{NH}_{4} \mathrm{OH} 6 \mathrm{~g} / \mathrm{L}, \mathrm{Na}_{2^{-}}$ EDTA $1 \mathrm{~g} / \mathrm{L}, \quad \mathrm{MnCl}_{2} .4 \mathrm{H}_{2} \mathrm{O} \quad 1.81 \mathrm{~g} / \mathrm{L}, \quad \mathrm{ZnSO}_{4} .7 \mathrm{H}_{2} \mathrm{O}$ $0.222 \mathrm{~g} / \mathrm{L}, \quad \mathrm{Na}_{2} \quad \mathrm{MoO}_{4} .2 \mathrm{H}_{2} \mathrm{O} \quad 0.39 \mathrm{~g} / \mathrm{L}, \quad \mathrm{CuSO}_{4} .5 \mathrm{H}_{2} \mathrm{O}$ $0.08 \mathrm{mg} / \mathrm{L}, \mathrm{H}_{3} \mathrm{BO}_{3} 2.86 \mathrm{~g} / \mathrm{L}$.

Fog medium (Kothari et al. 2012); $\mathrm{KNO}_{3} 2000 \mathrm{mg} / \mathrm{L}$, $\mathrm{K}_{2} \mathrm{HPO}_{4} 200 \mathrm{mg} / \mathrm{L}, \mathrm{MgSO}_{4} .7 \mathrm{H} 2 \mathrm{O} 200 \mathrm{mg} / \mathrm{L}, \mathrm{CaCl}_{2} .2 \mathrm{H}_{2} \mathrm{O}$ $100 \mathrm{mg} / \mathrm{L}$, Fe-EDTA solution $5 \mathrm{ml} / \mathrm{L}$ (Fe-EDTA solution: $745 \mathrm{mg} \mathrm{Na} \mathrm{Na}_{2}$-EDTA and $557 \mathrm{mg} \mathrm{FeSO}_{4} \cdot 7 \mathrm{H}_{2} \mathrm{O}$ in $100 \mathrm{ml}$ distilled water), Trace metal solution $1 \mathrm{ml} / \mathrm{L}$ (Trace metal solution: $\mathrm{H}_{3} \mathrm{BO}_{3} \quad 2.86 \mathrm{~g} / \mathrm{L}, \quad \mathrm{MnCl}_{2} .4 \mathrm{H}_{2} \mathrm{O} \quad 1.81 \mathrm{~g} / \mathrm{L}$, $\mathrm{ZnSO}_{4} \cdot 7 \mathrm{H}_{2} \mathrm{O} \quad 0.222 \mathrm{~g} / \mathrm{L}, \quad \mathrm{Na}_{2} \quad \mathrm{MoO}_{4}-2 \mathrm{H}_{2} \mathrm{O} \quad 0.39 \mathrm{~g} / \mathrm{L}$, $\mathrm{CuSO}_{4} .5 \mathrm{H}_{2} \mathrm{O} 0.08 \mathrm{~g} / \mathrm{L}$,).

$M_{4} N$ medium (Yanagi et al. 1995); $\mathrm{KNO}_{3} 5000 \mathrm{mg} / \mathrm{L}$, $\mathrm{K}_{2} \mathrm{HPO}_{4} \quad 1250 \mathrm{mg} / \mathrm{L}, \quad \mathrm{MgSO}_{4} .7 \mathrm{H}_{2} \mathrm{O} \quad 25000 \mathrm{mg} / \mathrm{L}$, $\mathrm{CaCl}_{2} .2 \mathrm{H}_{2} \mathrm{O} 100 \mathrm{mg} / \mathrm{L}, \quad \mathrm{FeSO}_{4} .7 \mathrm{H}_{2} \mathrm{O} 30 \mathrm{mg} / \mathrm{L}$, Trace metal solution $1 \mathrm{ml} / \mathrm{L}$ (Trace metal solution:, $\mathrm{MnCl}_{2} \cdot 4 \mathrm{H}_{2} \mathrm{O}$ $1.81 \mathrm{~g} / \mathrm{L}, \mathrm{ZnSO}_{4} .7 \mathrm{H}_{2} \mathrm{O} 0.222 \mathrm{~g} / \mathrm{L}, \mathrm{Na}_{2} \mathrm{MoO}_{4} .2 \mathrm{H}_{2} \mathrm{O} 0.39 \mathrm{~g} /$ $\left.\mathrm{L}, \mathrm{CuSO}_{4} .5 \mathrm{H}_{2} \mathrm{O} 0.08 \mathrm{~g} / \mathrm{L}, \mathrm{H}_{3} \mathrm{BO}_{3} 2.86 \mathrm{~g} / \mathrm{L}\right)$. 
All the Chlorella species were cultured in $250 \mathrm{ml}$ Erlenmeyer flasks containing $125 \mathrm{ml}$ liquid using above four nutrient media composition under cool florescent light $(\sim 2500 \mathrm{~lx})$ at $24^{\circ} \mathrm{C}\left( \pm 1{ }^{\circ} \mathrm{C}\right)$ and $16: 8$ light dark cycle in a photo bioreactor.

\section{Effect of organic carbon sources on biomass production and lipid accumulation}

Ignoring $\mathrm{CO}_{2}$ in air, the effect of different organic carbon sources like glucose, glycerol, sodium acetate, and sucrose) was also tested with selected BG-11 growth media. Carbon content of different organic sources was kept same $(0.5 \mathrm{~g} /$ L) during the experiment. Sterile media was used during whole experiment. The experiments were conducted at room temperature $\left(\sim 22-30{ }^{\circ} \mathrm{C}\right)$ under cool white, fluorescent light for 14 days. 11 bottle was used as a lab scale photobioreactor. Working volume of photobioreactor was kept $600 \mathrm{ml}$ with $10 \%(\mathrm{v} / \mathrm{v})$ inoculum. The photoperiod was set 16:8 light: dark period with fluorescent illumination of $3000 \mathrm{~lx}$. The culture was aerated $(200 \mathrm{ml} / \mathrm{min})$ by aquarium pump to avoid settling of microalgal biomass. The experiment was performed for 14 days at batch scale. Initial $\mathrm{pH}$ of medium was adjusted to be 7.0.

\section{Analytical methods}

\section{Cultivation parameters}

Microalgae growth was determined by measuring the optical density at $680 \mathrm{~nm}$ (OD680) using UV-visible spectrophotometer (Thermo Scientific) daily and related to algal biomass (g/L). For biomass estimation $10 \mathrm{ml}$ sample containing algae was filtered through pre-weighted Whatman $\mathrm{GF} / \mathrm{C}$ glass fiber filter and dried in oven at $60{ }^{\circ} \mathrm{C}$ until constant weight. The dry weight of algae is determined by subtracting from final weight of whatman GF/C glass fiber filter with algae to initial weight.

The biomass productivity $\mathrm{P}(\mathrm{mg} / \mathrm{L} /$ day) was calculated by following equation:

$P=\frac{\mathrm{W}_{2}-\mathrm{W}_{1}}{t}$

where, $\mathrm{W}_{1}$ was the initial biomass concentration, $\mathrm{W}_{2}$ was the biomass concentration at the last day of cultivation, $t$ was the cultivation time.

\section{Lipid extraction and measurement}

Lipid was extracted by applying Folch extraction method (Folch et al. 1957). According to this method, a weighted amount of biomass $(0.250 \mathrm{mg})$ was dissolved in $5 \mathrm{ml}$ chloroform/methanol $(2: 1 \mathrm{v} / \mathrm{v})$ and vortex for $30 \mathrm{~s}$. This was followed by agitating the mixture for $15-20 \mathrm{~min}$ at room temperature. The mixture was then centrifuged at $8000 \mathrm{rpm}$ for $10 \mathrm{~min}$ to separate cell debris from supernatant. This supernatant was washed by $0.9 \% \mathrm{NaCl}$ solution and vortex for few seconds. The mixture was centrifuged at $3000 \mathrm{rpm}$ for $5 \mathrm{~min}$. Lower chloroform layer with lipid was removed carefully and collected in $20 \mathrm{ml}$ pre-weighted glass vial. The residue was re-extracted with $2.5 \mathrm{ml}$ chloroform/methanol $(1: 1 \mathrm{v} / \mathrm{v})$ thrice as stated above. The supernatant was collected in same vial. The solvent was then dried at $65{ }^{\circ} \mathrm{C}$ in oven until constant weight of lipid was achieved. The lipid content was calculated gravimetrically. The lipid productivity $(\mathrm{mg} / \mathrm{L} / \mathrm{d})$ was calculated by the following equation:

Lipid productivity

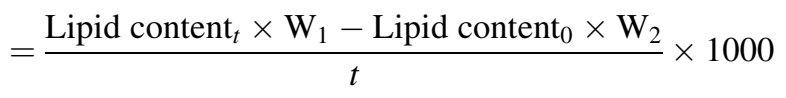

where Lipid content $t_{t}$ was the lipid content at the last day of cultivation and Lipid content $_{0}$ was the initial lipid content in algal cells.

\section{Fatty acid profile analysis}

Fatty acid extracted by Folch method was converted to their methyl esters by transesterification. Lipid was dissolved in $1 \mathrm{ml}$ of $1 \% \mathrm{NaOH}$ in $\mathrm{CH}_{3} \mathrm{OH}$ and heated for $55{ }^{\circ} \mathrm{C}$ for $15 \mathrm{~min}$. Then, $2 \mathrm{ml}$ of $5 \%$ methanolic $\mathrm{HCl}$ was added and again heated for $15 \mathrm{~min}$ at $55{ }^{\circ} \mathrm{C}$. The obtained product mixture was washed with distilled water. Fatty acid methyl esters (FAME) were extracted using $1 \mathrm{ml}$ hexane thrice and evaporated to dryness (Kumari et al. 2011). FAME was re-dissolved in $200 \mu \mathrm{l}$ hexane and analyzed using a Gas chromatograph (Nucon 5700 series) equipped with Flame ionization detector (FID) using EOX column (serial no $5061 ; 30 \mathrm{~m} \times 0.25 \mathrm{~mm} \times 0.25 \mu \mathrm{m}$ ). Pure Nitrogen $(99.999 \%)$ used as carrier gas with a flow rate of $1 \mathrm{ml} / \mathrm{min}$ and pre-column pressure of $49.7 \mathrm{kPa}$. The initial temperature was set at $160{ }^{\circ} \mathrm{C}$ for $2 \mathrm{~min}$, followed by a $4{ }^{\circ} \mathrm{C} / \mathrm{min}$ ramp up to $240{ }^{\circ} \mathrm{C}$ and maintained for $50 \mathrm{~min}$. The injector and FID detector temperature was set at 240 and $220{ }^{\circ} \mathrm{C}$, respectively. FAME peaks were identified by the comparison of their retention time with authentic standard by GC and quantified by normalization. Methylated heptadecanoic acid was used as an internal standard.

\section{Prediction of fuel properties}

Fuel properties of biodiesel obtained from Chlorella spp. were examined with the help of following equations (Sinha et al. 2016) 


$$
\begin{aligned}
& \mathbf{S V}=\Sigma(560 \times N) / M_{\mathrm{W}} \\
& \mathbf{I V}=\Sigma(254 \times N \times D) / M_{\mathrm{W}} \\
& \mathbf{C N}=(46.3+5458 / \mathrm{SV})-(0.225 \times \mathrm{IV}) \\
& \mathbf{D U}=(\text { MUFA, wt \% })+(2 \times \text { PUFA, wt \% }) \\
& \mathbf{L C S F}=(0.1 \times \mathbf{C} 16: 0)+(0.5 \times \mathrm{C} 18: 0) \\
& +(1 \times \mathrm{C} 20: 0)+(2 \times \mathrm{C} 24: 0) \\
& \mathbf{C F P P}=(3.1417 \times \mathrm{LCSF})-16.477 \\
& \text { OS }=117: 9295 / X-2: 5905(\text { where } 0<X>100)
\end{aligned}
$$$$
\mathbf{C P}=(0.526 \times \mathbf{C} 16-4.992)
$$$$
\mathbf{P P}=(0.571 \times \mathbf{C} 16-12.240)
$$$$
\mathbf{H H V}(\mathbf{M J} / \mathbf{k g})=49: 43-0: 041 \times(\mathrm{SV})-0: 015(\mathrm{IV})
$$

where $N$ is the percentage of each fatty acid, $M_{\mathrm{W}}$ is the molecular mass of fatty acid, $M_{i}$ is the molecular mass of $i$ th fatty acid, $D$ is the number of double bonds, MUFA is monounsaturated fatty acids, PUFA is polyunsaturated fatty acid, CFPP is cold filter pluging point, OS oxidation stability, $\mathrm{CP}$ cloud point, $\mathrm{PP}$ pour point, $X$ is the percentage of linoleic and linolenic acids (wt \%) and HHV is the calorific value of FAME in $\mathrm{MJ} / \mathrm{Kg}$.

\section{Statistics}

The data were recorded in triplicates and represented as mean of three experiments with \pm standard deviation.

\section{Result and discussion}

\section{Characterization of microalgae strains}

Five strains of fresh water microalgae (Chlorella vulgaris, Chlorella minutissima, Chlorella pyrenoidosa, Chlorella sp. 1 and Chlorella sp. 2) selected for the laboratory experiments belong to the division of Chlorophyta and the class of Chlorophyceae. The pictures of all the five green microalgae were taken by an optical microscope (S1). One microalgae species was isolated from Dehradun region and identified morphologically. Characteristics and Morphological features of the isolated microalgae have its close similarity with genus Chlorella vulgaris, Chlorella minutissima, Chlorella pyrenoidosa, and chlorella sp. 2 and represented here as Chlorella sp. 1. The individual cells of the colonies were in the range of $2-10 \mu \mathrm{m}$. Microalgal cells were green color, unicellular, and spherical in shape.

\section{Screening and identification of efficient growth media for maximum lipid productivity}

All the microalgae species (Chlorella vulgaris, Chlorella minutissima, Chlorella pyrenoidosa, Chlorella sp. 1, and Chlorella sp. 2) were cultured in four media i.e. BG-11, BBM, Fog's and $\mathrm{M}_{4} \mathrm{~N}$ medium in $250 \mathrm{ml}$ Erlenmeyer flasks (conical flask) each containing $125 \mathrm{ml}$ media. The results revealed that all the microalgal species had approximately 2 days lag period and reached the exponential phase within 4-6 days in all the media. Microalgae cells achieved stationary phase within 15 days and after that cells growth was very slow as shown in Fig. 1. As each microalgal species shows different biochemical composition (e.g., protein, amino acids, carbohydrate, lipid, fatty acids, chlorophyll and carotenoids) in different media which is reflected by different optical density (OD) of samples. Hence, biomass dry weight (DW) does not correlate well with OD for different culture media or strains. To avoid this error, actual biomass concentration dry weight (DW) was used to study microalgae growth in different media. DW biomass concentration of all the five microalgae species at the stationary phase are shown Fig. 2. It was examined that highest biomass concentration of Chlorella vulgaris was in BG-11 $(1.64 \pm 0.07 \mathrm{~g} / \mathrm{L})$, followed by BBM $(1.58 \pm 0.05 \mathrm{~g} / \mathrm{L})$, Fog's medium $(1.33 \pm 0.03 \mathrm{~g} /$ L) and $\mathrm{M}_{4} \mathrm{~N}(1.30 \pm 0.04 \mathrm{~g} / \mathrm{L})$. Similarly, Chlorella minutissima $(1.52 \pm 0.03 \mathrm{~g} / \mathrm{L})$ and Chlorella sp. 1 $(1.39 \pm 0.05 \mathrm{~g} / \mathrm{L})$ also showed maximum biomass concentration in BG-11. But, in case of Chlorella pyrenoidosa and Chlorella sp. 2, biomass concentration was maximum $(1.69 \pm 0.02$ and $1.48 \pm 0.06 \mathrm{~g} / \mathrm{L}$, respectively) in Fog's medium. This can be explained by the fact that higher nitrogen concentration is favorable for increasing biomass growth ( $\mathrm{Li}$ et al. 2012). However, $\mathrm{M}_{4} \mathrm{~N}$ (having maximum nitrogen concentration) showed poor biomass concentration which is due to deleterious effect of nitrogen at higher concentrations ( $\mathrm{Li}$ et al. 2012).

Lipid content was reported as a percentage of lipids to biomass DW. Similar to biomass yield, significant variances in lipid content were found across strains and culture media. Lipid contents and productivity of all the five strains in different culture media are shown in Figs. 3 and 4, respectively. Maximum lipid content and productivity was found in BBM media for all the Chlorella species. The highest lipid content of $15.87 \pm 0.77 \%$ was found for Chlorella sp. 1 cultivated in BBM, followed by Chlorella vulgaris $\quad(15.57 \pm 1.44 \%), \quad$ Chlorella minutissima (12.95 $\pm 0.53 \%), \quad$ Chlorella pyrenoidosa (11.43 \pm $1.26 \%)$ and Chlorella sp. $2(9.64 \pm 0.86 \%)$ in BBM 

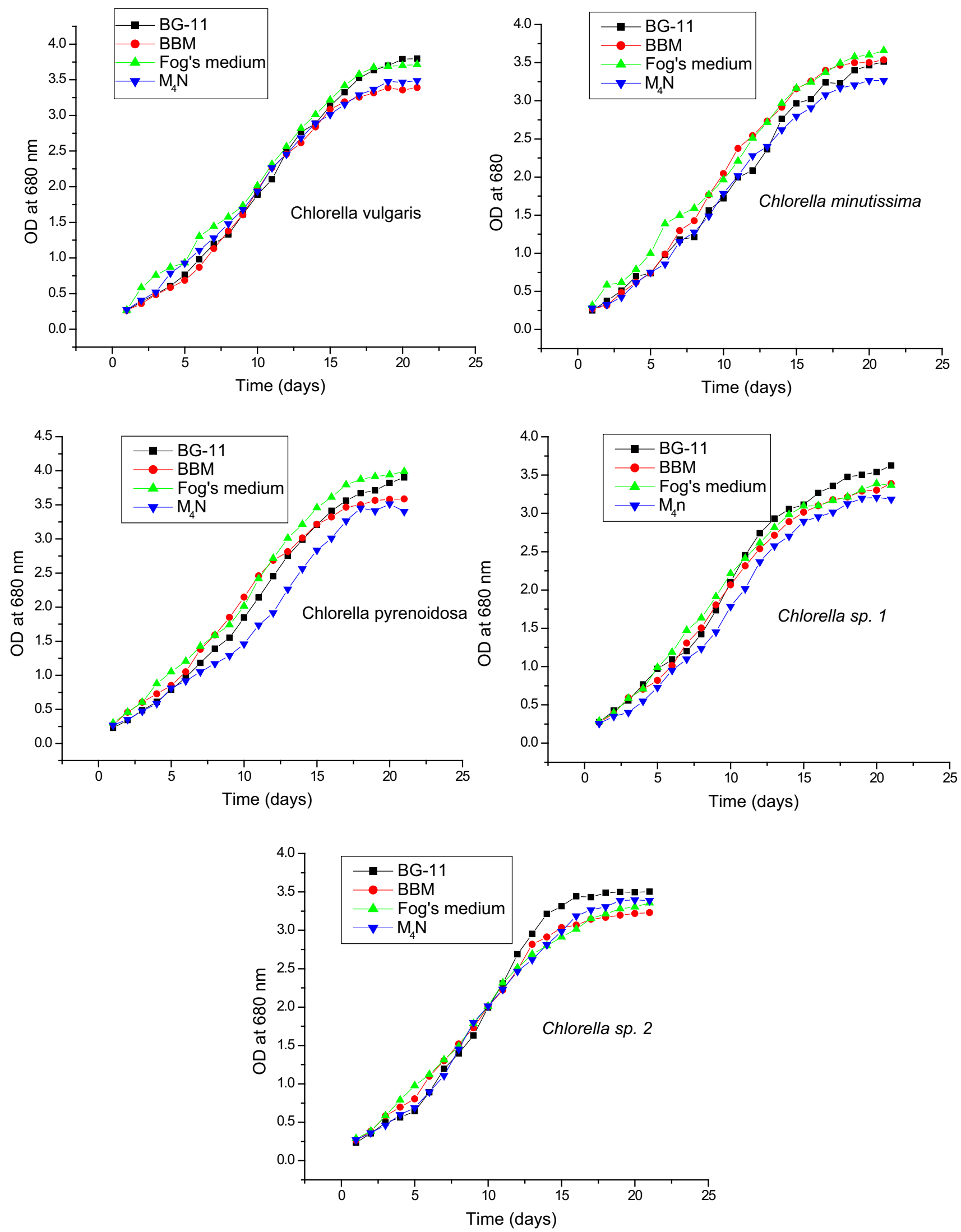

Fig. 1 OD of Chlorella vulgaris, Chlorella minutissima, Chlorella pyrenoidosa, Chlorella sp. 1 and Chlorella sp. 2 biomass in different nutrient media 


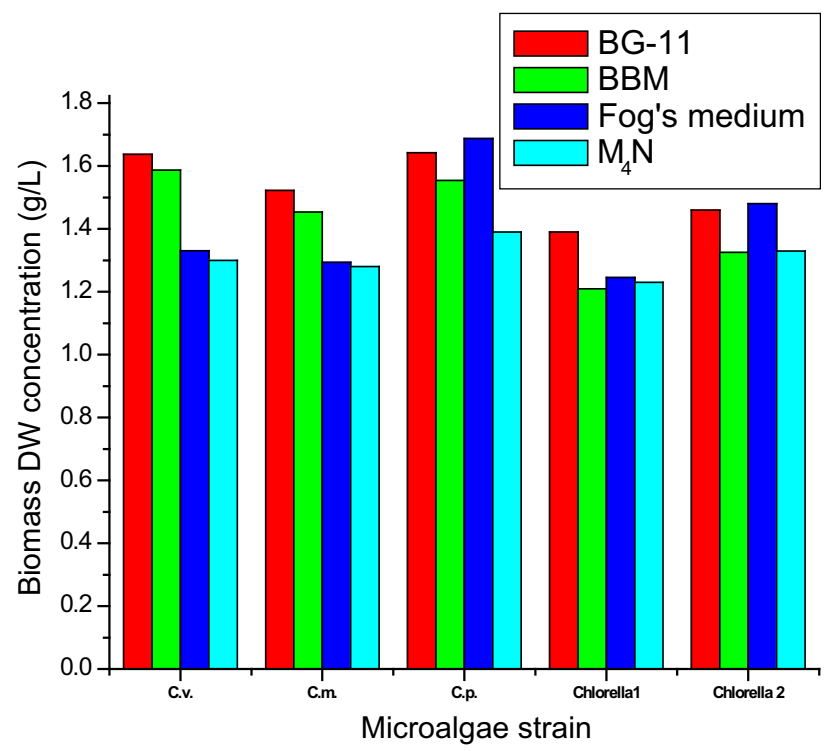

Fig. 2 Comparison of biomass DW of five microalgal strains in four culture media. $\mathrm{Cv}$, Chlorella vulgaris; $\mathrm{Cm}$, Chlorella minutissima; $\mathrm{Cp}$, Chlorella pyrenoidosa; Chlorella 1, Chlorella sp. 1 and Chlorella 2, Chlorella sp. 2

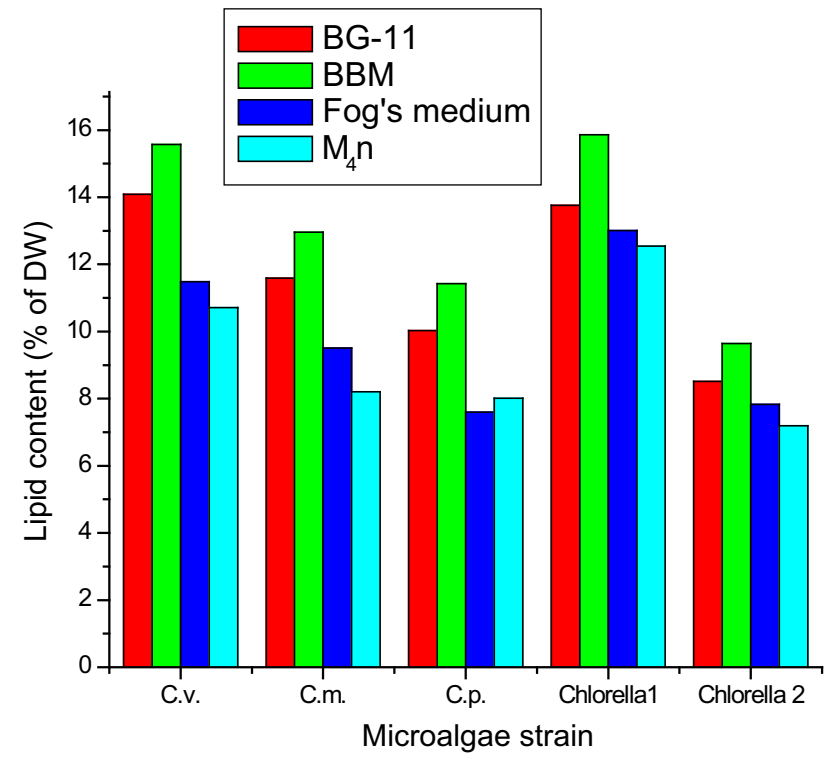

Fig. 3 Comparison of lipid content of five microalgal strains in four culture media. $\mathrm{Cv}$, Chlorella vulgaris; $\mathrm{Cm}$, Chlorella minutissima; $\mathrm{Cp}$, Chlorella pyrenoidosa; Chlorella 1, Chlorella sp. 1 and Chlorella 2, Chlorella sp. 2

medium. Minimum lipid content was observed in $\mathrm{M}_{4} \mathrm{~N}$ growth medium. Furthermore, all microalgae species showed highest lipid productivity in BBM growth media and lowest in $\mathrm{M}_{4} \mathrm{~N}$ medium. Among all the tested species, maximum lipid productivity was observed for Chlorella vulgaris $(12.35 \pm 0.37 \mathrm{mg} / \mathrm{L} / \mathrm{d})$, followed by Chlorella $\mathrm{sp}$. $1 \quad(9.56 \pm 0.43 \mathrm{mg} / \mathrm{L} / \mathrm{d}), \quad$ Chlorella minutissima $(9.41 \pm 0.67 \mathrm{mg} / \mathrm{L} / \mathrm{d}), \quad$ Chlorella pyrenoidosa $(8.88 \pm$

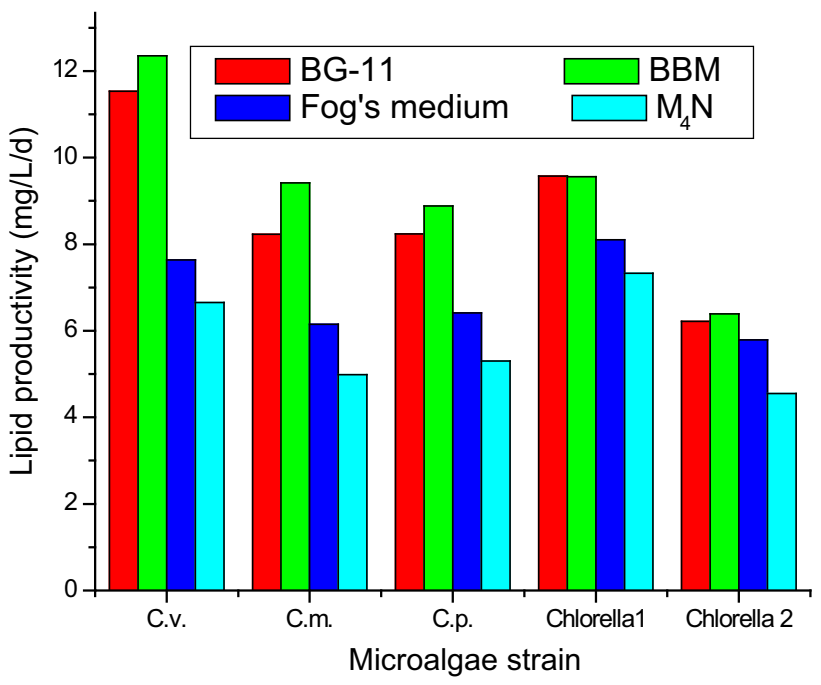

Fig. 4 Comparison of lipid productivity of five microalgal strains in four culture media. $\mathrm{Cv}$, Chlorella vulgaris; $\mathrm{Cm}$, Chlorella minutissima; Cp, Chlorella pyrenoidosa; Chlorella 1, Chlorella sp. 1 and Chlorella 2, Chlorella sp. 2

$0.41 \mathrm{mg} / \mathrm{L} / \mathrm{d})$ and Chlorella sp. $2(6.39 \pm 0.35 \mathrm{mg} / \mathrm{L} / \mathrm{d})$. These data are supported by the fact that nitrogen starvation condition results in more lipid accumulation (Converti et al. 2009; Chen et al. 2011; Feng et al. 2011; Kumari et al. 2011; Li et al. 2012). The selection of culture medium depends upon various factors viz. the target product, growth rate, and medium cost. However, nitrogen is the key factor in growth medium and also a limiting nutrient affecting the biomass growth and lipid productivity of various microalgae (Griffiths and Harrison 2009). Culture media comparison shows that on an average BBM gave highest lipid content and productivity, followed by BG-11, whereas Fog's medium and $\mathrm{M}_{4} \mathrm{~N}$ had the lowest. Generally, lipid content of microalgae increases when microalgae are subjected to unfavorable culture conditions, such as nutrient starvation (Converti et al. 2009; Chen et al. 2011; Feng et al. 2011). According to Li et al. (2012), the lipid yield of microalgae species can be improved by at least $300 \%$ under nitrogen limited conditions. Since, lipid production is the main aim of microalgae cultivation in this study, BBM and BG-11 are the preferred growth media. BBM had higher lipid content and productivity due to relatively lower nitrogen and phosphate concentrations, whereas, BG-11 medium being nitrogen rich medium has good potential to increase lipid productivity by applying nitrogen deficient condition (Li et al. 2012). Furthermore, total cost of chemicals to prepare 11 medium was found to be Rs. 0.784 and Rs. 0.472 for BG-11 and BBM growth media, respectively. When applying nitrogen deficient medium (suppose half concentration of nitrogen in case of BG-11) to culture algae, the cost of BG-11 preparation will be reduced up to Rs. 0.460. While BBM is already nitrogen 
deficient medium and further decrease in nitrogen concentration will results in reduction of total lipid productivity. Therefore, on the basis of potential of growth medium for enhancing lipid productivity and cost reduction, BG-11 had been considered as best medium in this study and used as culture medium for further study.

\section{Effect of carbon sources on microalgae growth and lipid accumulation}

In this study, all the Chlorella species were grown in optimized BG-11 medium (optimized in previous research paper, Sharma et al. 2016) with different organic carbon sources at room temperature and 16:8 light:dark cycle. The supplemented organic carbon sources were glucose (7.22 mM), glycerol (14.13 mM), sodium acetate $(21.09 \mathrm{mM})$ and sucrose $(3.51 \mathrm{mM})$ with fixed amount of carbon content $(0.5 \mathrm{~g} / \mathrm{L})$.

Among the tested organic carbon sources, glucose was found the best carbon source for mixotrophic growth of all the Chlorella strains, followed by glycerol, sodium acetate and sucrose. The study showed that addition of glucose results in maximum biomass production of 2.08, 2.04, 1.84, 1.53 and $1.43 \mathrm{~g} / \mathrm{L}$ for Chlorella vulgaris, Chlorella minutissima, Chlorella pyrenoidosa, Chlorella sp. 1 and Chlorella sp. 2 at stationary phase (Fig. 5). However, all the microalgae species achieved maximum biomass concentration within 8-11 days in the culture medium supplemented with glucose and the average highest biomass productivity were found $274.46 \mathrm{mg} / \mathrm{L} /$ day for Chlorella vulgaris, followed by $239.15 \mathrm{mg} / \mathrm{L} /$ day for Chlorella minutissima, $191.28 \mathrm{mg} / \mathrm{L} / \mathrm{day}$ for Chlorella pyrenoidosa, $162.52 \mathrm{mg} / \mathrm{L} /$ day for Chlorella sp. 1 and $111.36 \mathrm{mg} / \mathrm{L} / \mathrm{day}$ for Chlorella sp. 1, respectively. Biomass concentration of all the microalgal stains was poor in sucrose culture medium at stationary phase. These results are in agreement with previous report that glucose is an efficient trigger to increase biomass productivity of the microalgae (PerezGarcia et al. 2011a; Cheirsilp and Torpee 2012; Sun et al. 2014). This can be explained by the fact that glucose is the raw material for photosynthesis and under mixotrophic growth, it can be utilized in the presence of light for energy metabolism for ATP and $\mathrm{NAD}(\mathrm{P}) \mathrm{H}$ production, and, therefore, biomass growth can be accelerated (Yang et al. 2000). On the other hand, lipid contents of four Chlorella strains (Chlorella vulgaris, Chlorella minutissima, Chlorella pyrenoidosa, Chlorella sp. 1) were significantly higher in culture medium supplemented with glycerol as carbon source and followed by sodium acetate, glucose, and sucrose organic carbon sources, while Chlorella sp. 2 showed maximum lipid content in sodium acetate culture medium (Fig. 6). Maximum lipid production was $24.32 \%$ for Chlorella vulgaris, $18.59 \%$ for Chlorella minutissima,
$17.10 \%$ for Chlorella pyrenoidosa and $23.31 \%$ for Chlorella sp. 1 in glycerol culture medium while $13.42 \%$ for Chlorella sp. 2 in sodium acetate. Lipid production was found to be lowest in case of sucrose carbon source for all the tested microalgal strains except Chlorella sp. 2 which showed exceptional behavior and minimum lipid content of this species was in glycerol. Maximum lipid yield observed for the tested microalgal strains was $490.74 \mathrm{mg} / \mathrm{L}$ for Chlorella vulgaris, $369.13 \mathrm{mg} / \mathrm{L}$ for Chlorella minutissima, $282.59 \mathrm{mg} / \mathrm{L}$ for Chlorella pyrenoidosa, and $325.4 \mathrm{mg} / \mathrm{L}$ for Chlorella sp. 1 in glycerol culture medium which was more than twofolds higher in comparison to control culture (phototrophic culture) for all these species. On the other hand, Chlorella sp. 2 had shown highest lipid yield $(188.58 \mathrm{mg} / \mathrm{L})$ in glucose. This can be explained by the fact that glucose is a simple hexose monosaccharide, which is first catabolized into glucose-6-phosphate (important intermediate product for various metabolic precursors) and subsequently to pyruvate through anaerobic glycolysis process, then it enters into tricarboxylic acid cycle (TCA cycle) followed by mitochondrial oxidative phosphorylation for ATPs production (Lu et al. 2011). On the other hand, glycerol enters the cells by simple diffusion without any extra energy, does not behave as a source of carbons for biosynthesis (Perez-Garcia et al. 2011b). The pentose phosphate pathway (PPP) is inhibited during glycerol assimilation (Chen et al. 2011). More glycerol would be used in the Embden-Meyerh of pathway (EMP), and then sacrifice to generate lipids. Furthermore, glycerol is a substrate for triacylglycerol (TAG) synthesis. Overall, it was found that different biomass and lipid productions of all the five microalgal species were due to their different metabolic pathways of carbon and energy sources. Lipid productivity of Chlorella vulgaris $(50.17 \mathrm{mg} / \mathrm{L} / \mathrm{d})$, Chlorella pyrenoidosa $(23.91 \mathrm{mg} / \mathrm{L} / \mathrm{d})$ and Chlorella sp. 1 (28.69 mg/L/d) was observed best in glycerol medium, whereas Chlorella minutissima $(35.8 \mathrm{mg} / \mathrm{L} / \mathrm{d})$ and Chlorella sp. 2 (14.73 mg/L/d) showed maximum lipid productivity in glucose supplemented culture medium (Fig. 7). But higher cost of glucose is a major hurdle to microalgal biodiesel production economics. Additionally, glycerol is much cheaper than glucose and also a byproduct of biodiesel production. Therefore, utilizing glycerol for microalgae cultivation may be a good approach for recycling it and reduction of biodiesel production cost. Hence, glycerol is more promising candidate to make algae biodiesel economically viable.

\section{Predicted fuel properties of biodiesel extracted from Chlorella species}

Fuel properties of biodiesel are highly influenced by fatty acid composition of algae. Fatty acid composition of 

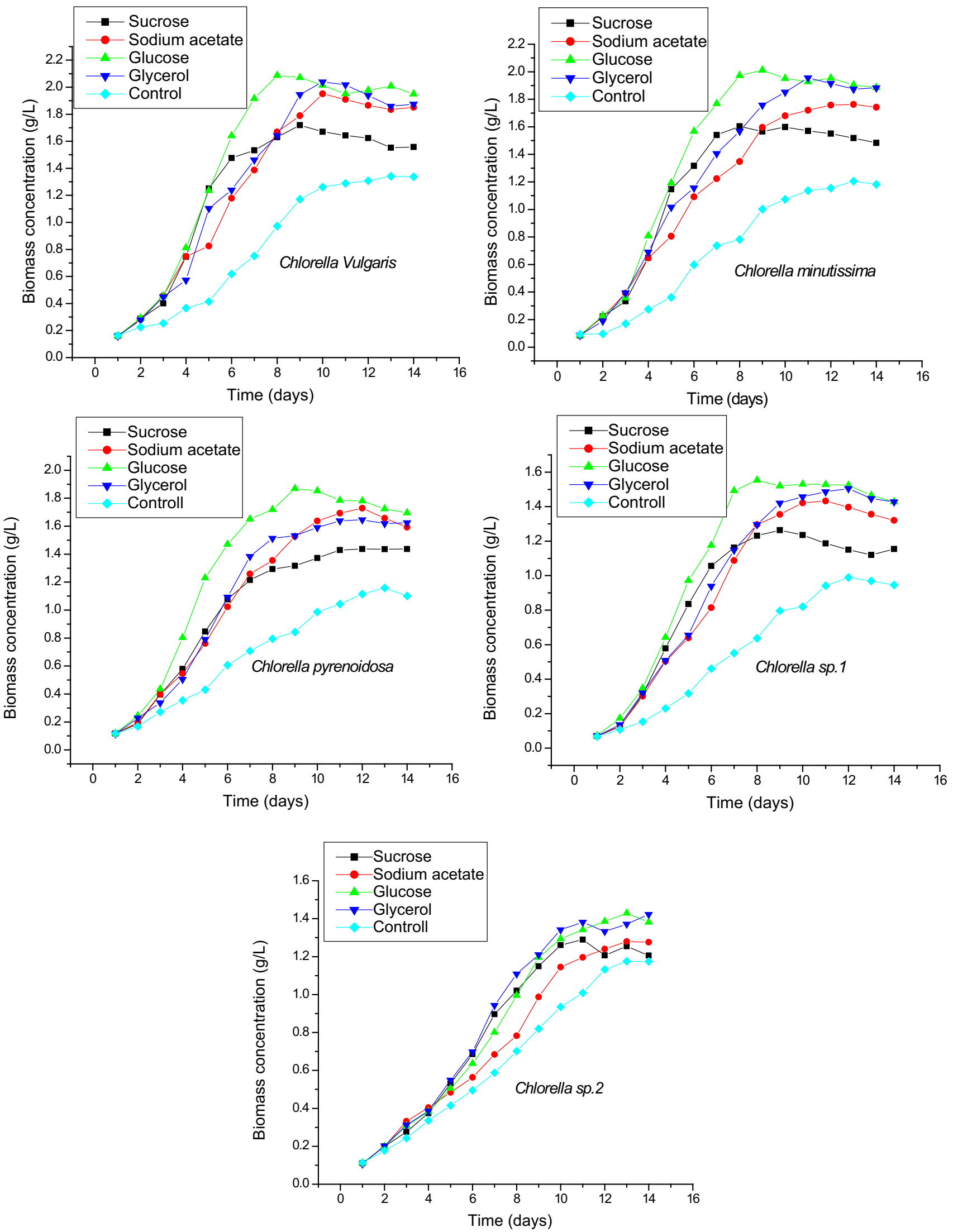
४Fig. 5 Biomass growths of Chlorella vulgaris, Chlorella minutissima, Chlorella pyrenoidosa, Chlorella sp. 1 and Chlorella sp. 2 under different carbon sources

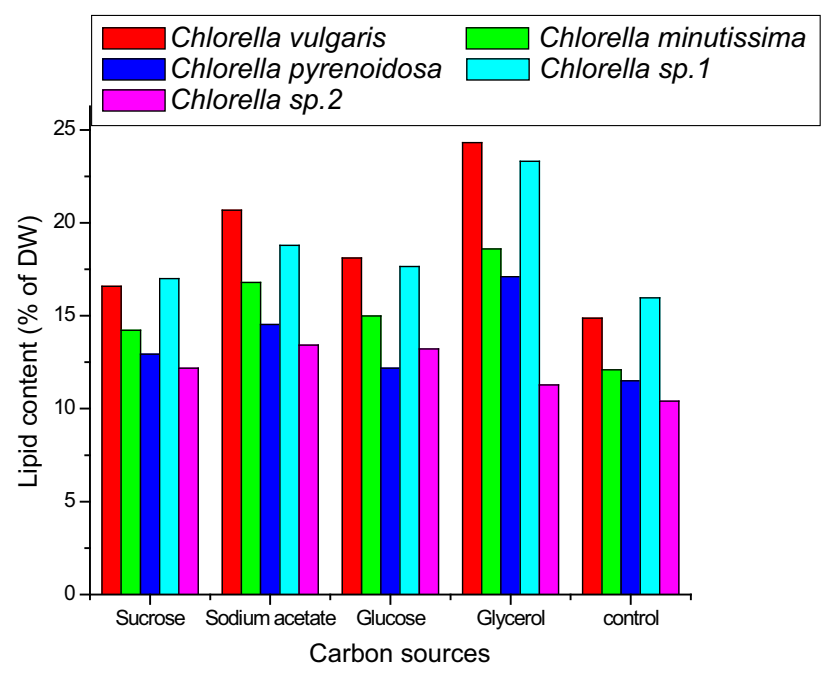

Fig. 6 Lipid contents of Chlorella vulgaris, Chlorella minutissima, Chlorella pyrenoidosa, Chlorella sp. 1 and Chlorella sp. 2 under different carbon sources

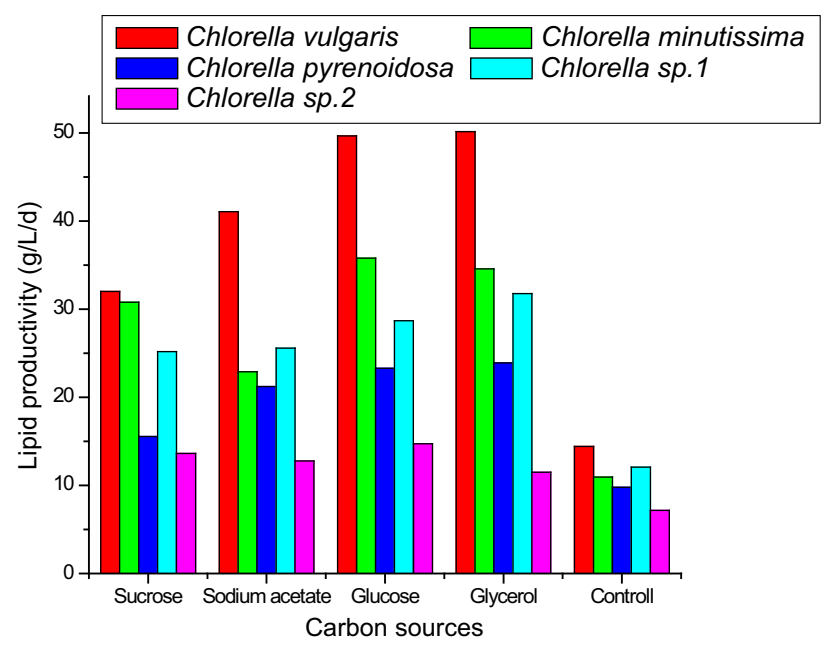

Fig. 7 Lipid productivities of Chlorella vulgaris, Chlorella minutissima, Chlorella pyrenoidosa, Chlorella sp. 1 and Chlorella sp. 2 under different carbon sources

Chlorella vulgaris, Chlorella minutissima, Chlorella pyrenoidosa Chlorella sp. 1 and Chlorella sp. 2 is shown in Table 1. Results showed that Chlorella pyrenoidosa contains higher saturated FAME $(45.07 \%)$ than Chlorella vulgaris $(31.73 \%)$, Chlorella minutissima (35.14\%), Chlorella sp. 1 (33.14 \%) and Chlorella sp. 2 (44.94\%), whereas mono unsaturated fatty acid were found maximum for Chlorella minutissima (38.01\%), followed by Chlorella sp. 2 (34.53\%), Chlorella pyrenoidosa (33.42\%),
Chlorella vulgaris $(21.76 \%)$ and Chlorella sp. 2 $(17.34 \%)$. Further analysis showed that polyunsaturated fatty acid were $36.14,25.33,19.87,32.36$ and $36.19 \%$ in Chlorella vulgaris, Chlorella minutissima, Chlorella pyrenoidosa, Chlorella sp. 1 and Chlorella sp. 2, respectively. Previous research showed that ideal biodiesel would have low level of polyunsaturated and saturated fatty acids to support the favorable oxidative stability and cold flow problem (Knothe 2009; Hoekman et al. 2012). Therefore, presence of monounsaturated fatty acids, such as palmitoleic acid (16:1) and oleic acid (18:1), play a big role for giving the best compromise between oxidative stability and cold flow (Knothe 2009; Hoekman et al. 2012). In this study, monounsaturated fatty acids were analyzed from 17.34 to $38.01 \%$ for the tested Chlorella strains. Among the tested species, Chlorella minutissima showed maximum monounsaturated fatty acids $(38.01 \%)$ and Chlorella sp. 2 showed minimum monounsaturated fatty acids (17.34\%).

It was reported that biodiesel composition enriched with C16-C18 fatty acids have good fuel properties (Knothe 2009). As shown in Table 1, fatty acid compositions of all Chlorella strains have major constituent of palmitic (16:0), stearic (18:0), oleic (18:1), linoleic (18:2), and linolenic (18:3) acids. The presence of more polyunsaturated FAME results in lower oxidation stability of biodiesel. This can be explained by the fact that polyunsaturated FAME contains reactive sites which are susceptible for attack of free radicals during oxidation reaction. According to European standards EN14214, for an ideal biodiesel the percentage of linolenic acid (C18:3) and polyunsaturated FA ( $>4$ double bond) should not increase 12 and $1 \%$, respectively (Knothe 2009). Maximum linolenic acid (C18:3) was found in Chlorella sp. 2. (14.20\%) while minimum was for Chlorella vulgaris $(4.55 \%)$. Furthermore, polyunsaturated FA ( $>4$ double bond) was absent in all the Chlorella strains.

Table 2 shows predicted fuel properties of Chlorella vulgaris, Chlorella minutissima Chlorella pyrenoidosa Chlorella sp. 1 and Chlorella sp. 2. Iodine value is the measurement of total unsaturation in biodiesel. Higher Iodine Value of the biodiesel may result in the polymerization of glycerides and deposition of lubricant in the engine (Francisco et al. 2010). According to European standards EN 14214, iodine value of biodiesel should not be more than $120 \mathrm{~g} \mathrm{I} / 100 \mathrm{~g}$. In this study, maximum iodine value was observed for Chlorella sp. 1 (99.92) while Chlorella pyrenoidosa showed minimum iodine value (68.90). Cetane number indicates combustion behavior of fuel in engine. The higher cetane value results in better combustion of fuel, lower NOx emission, less occurrence of knocking and easier start- up of engine. According to ASTMD6751, European (EN 14214) and 
Table 1 Fatty acid composition of Chlorella vulgaris, Chlorella minutissima, Chlorella pyrenoidosa, Chlorella sp. 1 and Chlorella sp. 2

\begin{tabular}{|c|c|c|c|c|c|}
\hline Fatty acid composition (\%) & Chlorella vulgaris & Chlorella minutissima & Chlorella pyrenoidosa & Chlorella sp. 1 & Chlorella sp. 2 \\
\hline C 8:0 & 0.1746 & 0.5943 & nd & 0.9883 & 0.4798 \\
\hline C $10: 0$ & 0.5171 & 2.8572 & 0.2105 & 1.8319 & 0.7548 \\
\hline C $12: 0$ & nd & 2.1761 & 1.8167 & 1.2387 & 2.6925 \\
\hline C $14: 0$ & 3.3011 & 2.8349 & 7.2533 & 2.3923 & 0.4662 \\
\hline C 16:0 & 21.5492 & 19.9060 & 28.6448 & 22.0379 & 36.1705 \\
\hline C $16: 1$ & 0.1747 & 9.4912 & nd & 4.9447 & 1.5880 \\
\hline C $18: 0$ & 5.0270 & 4.6787 & 7.1502 & 3.7954 & 5.757 \\
\hline C $18: 1$ & 21.5925 & 28.5275 & 33.4208 & 29.5875 & 15.7582 \\
\hline C $18: 2$ & 31.5895 & 17.8802 & 14.4817 & 18.1586 & 30.6374 \\
\hline C $18: 3$ & 4.5529 & 7.4552 & 5.3940 & 14.2094 & 5.5537 \\
\hline C $20: 0$ & 0.4816 & 0.5592 & nd & 0.7173 & 0.6234 \\
\hline C 22:0 & 0.6832 & 1.5337 & nd & 0.1479 & nd \\
\hline Saturated fatty acids & 31.7338 & 35.1401 & 45.0755 & 33.1497 & 44.9442 \\
\hline Mono unsaturated fatty acids & 21.7672 & 38.0187 & 33.4208 & 34.5322 & 17.3462 \\
\hline poly unsaturated fatty acids & 36.1424 & 25.3354 & 19.8757 & 32.368 & 36.1911 \\
\hline
\end{tabular}

Table 2 Fuel properties of biodiesel produced from Chlorella vulgaris, Chlorella minutissima, Chlorella pyrenoidosa, Chlorella sp. 1 and Chlorella sp. 2

\begin{tabular}{|c|c|c|c|c|c|}
\hline Fatty acid composition (\%) & Chlorella vulgaris & Chlorella minutissima & Chlorella pyrenoidosa & Chlorella sp. 1 & Chlorella sp. 2 \\
\hline Saponification value (mg $\mathrm{KOH} \mathrm{g}^{-} 1$ oil) & 178.68 & 199.94 & 197.21 & 201.63 & 198.48 \\
\hline Iodine value $\left(\mathrm{g} \mathrm{I}_{2} 100 \mathrm{~g}^{-1}\right.$ oil $)$ & 87.73 & 85.22 & 68.90 & 99.92 & 84.95 \\
\hline Cetane number & 57.10 & 54.42 & 58.47 & 50.88 & 54.68 \\
\hline DU $(\%)$ & 94.05 & 88.68 & 73.17 & 99.26 & 89.72 \\
\hline $\operatorname{LCSF}\left({ }^{\circ} \mathrm{C}\right)$ & 5.15 & 4.88 & 6.43 & 4.81 & 7.11 \\
\hline CFPP $\left({ }^{\circ} \mathrm{C}\right)$ & -0.29 & -1.11 & 3.75 & -1.33 & 5.88 \\
\hline Oxidation stability (h) & 5.8 & 7.2 & 8.5 & 6.2 & 5.8 \\
\hline Cloud point $\left({ }^{\circ} \mathrm{C}\right)$ & 6.43 & 10.47 & 10.07 & 9.20 & 14.86 \\
\hline Pour point $\left({ }^{\circ} \mathrm{C}\right)$ & 0.16 & 4.54 & 4.11 & 3.16 & 9.32 \\
\hline Higher heating value $(\mathrm{MJ} / \mathrm{kg})$ & 40.78 & 39.95 & 40.31 & 39.66 & 40.01 \\
\hline
\end{tabular}

Australian standard and National Petroleum Agency (ANP255) standard the minimum cetane value should be 47, 51 and 45, respectively. In this study the cetane value of Chlorella vulgaris, Chlorella minutissima, Chlorella pyrenoidosa, Chlorella sp. 1 and Chlorella sp. 2 is found $57.10,54.42,58.47,50.88$ and 54.68 which satisfied the above standards. Oxidation stability of biodiesel depends of presence of polyunsaturated FAME in biodiesel. This can be explained by the fact that polyunsaturated FAME contains reactive sites which are susceptible for attack of free radicals during oxidation reaction. According to EN 14214 , the oxidative stability should be above $6 \mathrm{~h}$. In this case, oxidation stability of five strains recorded 5.8-8.5 h. Cold fuel properties, such as cold filter plugging point, cloud point and pour point, are the most important properties for low temperatures applications. CP is the temperature at which crystallization begins and PP at which fuel no longer pours. These properties are highly affected by the presence of saturated FAME in biodiesel. Higher value of saturated FAME will result in poor cold properties. ASTM D6751 specifies CP range -3 to $12{ }^{\circ} \mathrm{C}$ and $\mathrm{PP}-15$ to $20{ }^{\circ} \mathrm{C}$. Five Chlorella strains examined in this study showed $\mathrm{CP}$ ranges from 6.43 to $14.86{ }^{\circ} \mathrm{C}$ and $\mathrm{PP}$ from 0.16 to $9.32{ }^{\circ} \mathrm{C}$. Calorific value is the indication of energy produced by the combustion of fuel and it was found to be maximum $(40.78 \mathrm{MJ} / \mathrm{Kg})$ for Chlorella vulgaris and minimum for followed by Chlorella spl (39.66 MJ/Kg). 


\section{Conclusion}

This study investigates the effect of various growth media and organic carbon sources on biomass and lipid production potential of five Chlorella species (Chlorella vulgaris, Chlorella minutissima, Chlorella pyrenoidosa, Chlorella sp. 1 and Chlorella sp. 2). The results revealed that all the species showed good potential for lipid production in BG11 supplemented with glycerol in comparison to controlled medium. However, maximum lipid yield was observed for Chlorella vulgaris $(490.74 \pm 12.30 \mathrm{mg} / \mathrm{L})$ among all the tested species. On the basis of lipid productivity, fatty acid composition and fuel properties, it is observed that Chlorella vulgaris showed good potential in BG-11 growth media supplemented with glycerol under mixotrophic condition for biodiesel production, but it further needs research for the optimization of $\mathrm{C}: \mathrm{N}: \mathrm{P}$ ratio for large-scale biodiesel production.

Acknowledgments Authors are highly thankful to our Chancellor Prof. S. J. Chopra, Former Vice Chancellor Dr. Parag Diwan, Vice Chancellor Dr. Shrihari, University of Petroleum and Energy Studies, Dehradun and R \& D department for their continuous encouragement and valuable mentorship.

\section{Compliance with ethical standards}

Conflict of interest The authors declare that they have no conflict of interest.

Open Access This article is distributed under the terms of the Creative Commons Attribution 4.0 International License (http:// creativecommons.org/licenses/by/4.0/), which permits unrestricted use, distribution, and reproduction in any medium, provided you give appropriate credit to the original author(s) and the source, provide a link to the Creative Commons license, and indicate if changes were made.

\section{References}

Bhatnagar A, Chinnasamy S, Singh M, Das KC (2011) Renewable biomass production by mixotrophic algae in the presence of various carbon sources and wastewaters. Appl Energy 88:3425-3431. doi:10.1016/j.apenergy.2010.12.064

Cheirsilp B, Torpee S (2012) Enhanced growth and lipid production of microalgae under mixotrophic culture condition: effect of light intensity, glucose concentration and fed-batch cultivation. Bioresour Technol 110:510-516. doi:10.1016/j.biortech.2012. 01.125

Chen CY, Yeh KL, Aisyah R et al (2011) Cultivation, photobioreactor design and harvesting of microalgae for biodiesel production: a critical review. Bioresour Technol 102:71-81. doi:10.1016/j. biortech.2010.06.159

Choi HJ, Yu SW (2015) Influence of crude glycerol on the biomass and lipid content of microalgae. Biotechnol Biotechnol Equip 29:506-513. doi:10.1080/13102818.2015.1013988

Converti A, Casazza AA, Ortiz EY et al (2009) Effect of temperature and nitrogen concentration on the growth and lipid content of
Nannochloropsis oculata and Chlorella vulgaris for biodiesel production. Chem Eng Process Process Intensif 48:1146-1151. doi:10.1016/j.cep.2009.03.006

Feng P, Deng Z, Hu Z, Fan L (2011) Lipid accumulation and growth of Chlorella zofingiensis in flat plate photobioreactors outdoors. Bioresour Technol 102:10577-10584. doi:10.1016/j.biortech. 2011.08.109

Folch J, Lees M, Sloane Stanley G (1957) A simple method of isolation and purification of total lipids from animal tissues. J Biol Chem 226:497-509

Francisco EC, Neves DB, Jacob-Lopes E, Franco TF (2010) Microalgae as feedstock for biodiesel production: carbon dioxide sequestration, lipid production and biofuel quality. J Chem Technol Biotechnol 85:395-403

Gao C, Zhai Y, Ding Y, Wu Q (2010) Application of sweet sorghum for biodiesel production by heterotrophic microalga Chlorella protothecoides. Appl Energy 87:756-761. doi:10.1016/j. apenergy.2009.09.006

Gim GH, Kim JK, Kim HS et al (2014) Comparison of biomass production and total lipid content of freshwater green microalgae cultivated under various culture conditions. Bioprocess Biosyst Eng 37:99-106. doi:10.1007/s00449-013-0920-8

Griffiths MJ, Harrison STL (2009) Lipid productivity as a key characteristic for choosing algal species for biodiesel production. J Appl Phycol 21:493-507. doi:10.1007/s10811-008-9392-7

Guillard RRL (2005) Purification Methods for Microalgae. In: Andersen RA (ed) Algal culturing techniques. Elesvier Academic Press, USA, pp 117-132

Hoekman SK, Broch A, Robbins C, Ceniceros E, Natarajan M (2012) Review of biodiesel composition, properties, and specifications. Renew. Sustain Energy Rev 16:143-169. doi:10.1016/j.rser. 2011.07.143

Huerlimann R, de Nys R, Heimann K (2010) Growth, lipid content, productivity, and fatty acid composition of tropical microalgae for scale-up production. Biotechnol Bioeng 107:245-257. doi:10.1002/bit.22809

Ilavarasi A, Mubarakali D, Praveenkumar R et al (2011) Optimization of various growth media to freshwater microalgae for biomass production. Biotechnology 10:540-545. doi:10.3923/biotech. 2011.540.545

Knothe G (2009) Improving biodiesel fuel properties by modifying fatty ester composition. Energy Environ Sci 2:759-766. doi:10. 1039/B903941D

Kothari R, Pathak VV, Kumar V, Singh DP (2012) Bioresource technology experimental study for growth potential of unicellular alga Chlorella pyrenoidosa on dairy waste water : an integrated approach for treatment and biofuel production. Bioresour Technol 116:466-470. doi:10.1016/j.biortech.2012. 03.121

Kumari P, Reddy CRK, Jha B (2011) Comparative evaluation and selection of a method for lipid and fatty acid extraction from macroalgae. Anal Biochem 415:134-144. doi:10.1016/j.ab.2011. 04.010

Lam MK, Lee KT (2012) Potential of using organic fertilizer to cultivate Chlorella vulgaris for biodiesel production. Appl Energy 94:303-308. doi:10.1016/j.apenergy.2012.01.075

Li Y, Fei X, Deng X (2012) Novel molecular insights into nitrogen starvation-induced triacylglycerols accumulation revealed by differential gene expression analysis in green algae Micractinium pusillum. Biomass Bioenergy 42:199-211. doi:10.1016/j. biombioe.2012.03.010

Lin T-S, Wu J-Y (2015) Effect of carbon sources on growth and lipid accumulation of newly isolated microalgae cultured under mixotrophic condition. Bioresour Technol 184:100-107. doi:10.1016/j.biortech.2014.11.005 
Lu J, Sheahan C, Fu P (2011) Metabolic engineering of algae for fourth generation biofuels production. Energy Environ Sci 4:2451-2466. doi:10.1039/C0EE00593B

Perez-Garcia O, Escalante FME, de-Bashan LE, Bashan Y (2011a) Heterotrophic cultures of microalgae: metabolism and potential products. Water Res 45:11-36. doi:10.1016/j.watres.2010.08. 037

Perez-Garcia O, Escalante FME, de-Bashan LE, Bashan Y (2011b) Heterotrophic cultures of microalgae: metabolism and potential products. Water Res 45:11-36. doi:10.1016/j.watres.2010.08. 037

Prajapati SK, Kaushik P, Malik P, Vijay VK (2013) Phycoremediation coupled production of algal biomass, harvesting and anaerobic digestion: possibilities and challenges. Biotechnol Adv 31:1408-1425. doi:10.1016/j.biotechadv.2013.06.005

Prajapati SK, Malik A, Vijay VK (2014) Comparative evaluation of biomass production and bioenergy generation potential of Chlorella spp. through anaerobic digestion. Appl Energy 114:790-797. doi:10.1016/j.apenergy.2013.08.021

Prathima Devi M, Venkata Subhash G, Venkata Mohan S (2012) Heterotrophic cultivation of mixed microalgae for lipid accumulation and wastewater treatment during sequential growth and starvation phases: effect of nutrient supplementation. Renew Energy 43:276-283. doi:10.1016/j.renene.2011.11.021

Sajid Z, Khan F, Zhang Y (2016) Process simulation and life cycle analysis of biodiesel production. Renew Energy 85:945-952. doi:10.1016/j.renene.2015.07.046
Sharma AK, Sahoo PK, Singhal S (2016) Comparative evolution of biomass production and lipid accumulation potential of Chlorella species grown in a bubble column photobioreactor. Biofuels. doi:10.1080/17597269.2015.1138040

Sinha SK, Gupta A, Bharalee R (2016) Production of biodiesel from freshwater microalgae and evaluation of fuel properties based on fatty acid methyl ester profile. Biofuels. doi:10.1080/17597269. 2015.1118781

Sun Y, Liu J, Xie T et al (2014) Enhanced lipid accumulation by Chlorella vulgaris in a two-stage fed-batch culture with glycerol. Energy Fuels 28:3172-3177. doi:10.1021/ef5000326

Wang W, Han F, Li Y et al (2014) Medium screening and optimization for photoautotrophic culture of Chlorella pyrenoidosa with high lipid productivity indoors and outdoors. Bioresour Technol 170:395-403. doi:10.1016/j.biortech.2014.08.030

Williams PRD, Inman D, Aden A, Heath GA (2009) Environmental and Sustainability factors associated with next-generation biofuels in the U.S.: what do we really know? Environ Sci Technol 43:4763-4775. doi:10.1021/es900250d

Yanagi M, Watanabe Y, Saiki H (1995) CO2 fixation by Chlorella sp. HA-1 and its utilization. Energy Convers Manag 36:713-716. doi:10.1016/0196-8904(95)00104-L

Yang C, Hua Q, Shimizu K (2000) Energetics and carbon metabolism during growth of microalgalcells under photoautotrophic, mixotrophic and cycliclight-autotrophic/dark-heterotrophic conditions. Biochem Eng J 6:87-102 